\title{
Teaching thin optical coating and optics education in developing country: a scenario in Bangladesh
}

\author{
K. A. Khan
}

K. A. Khan, "Teaching thin optical coating and optics education in developing country: a scenario in Bangladesh," Proc. SPIE 9665, Tenth International Topical Meeting on Education and Training in Optics and Photonics, 96651E (3 June 2007); doi: 10.1117/12.2207927

SPIE Event: Tenth International Topical Meeting on Education and Training in Optics and Photonics, 2007, Ottawa, Ontario, Canada 


\title{
Teaching thin optical coating and optics education in developing country - a scenario in Bangladesh
}

\author{
K. A. Khan
}

Department of Applied Physics \& Electronic Engineering, University of Rajshahi, Rajshahi-6205, Bangladesh. Tel: +880 721 750254, Fax: +880 721 740064,Email: kakhan_ru@yahoo.ca

\begin{abstract}
Optics education is an essential ingredient in building modern science and technology. As the rate of technological change accelerates, continuing optics education becomes more important than other. This talk is an account of a successfully continuing professional-education course on optics and optical coatings in the Department of Applied Physics \& Electronic Engineering, University of Rajshahi, - a scenario of optics education in Bangladesh. The foundation course on optics emphasizes in understanding of the basic principles of geometrical and physical optics through formal lectures and its practice through laboratory demonstrations. The Department of Applied Physics \& Electronic Engineering usually do local fabrication/ assembling of optics laboratory teaching aids. Students and technical staffs under the guidance of a Faculty staff member do equipment fabrication and assembling. This article describes some of the project-type set ups for performing experiments on (i) wavelengths of various spectral lines determination (ii) determination of unknown solution concentration (iii) determination of thickness of thin optical coating as well as (iv) determination of various optical parameters such as refractive index, optical band gap through the measurement of transmission and reflection spectra.
\end{abstract}

OCIS codes: (000.2060) Education, (080.2740) Geometrical optics, optical design, 310.6860) Thin Films, Optical Properties

\section{Introduction}

Science and technology have a major role in the development of today's society and civilization. The science of optics includes light emission, transmission, absorption, reflection, detection and amplification of light by optical devices and instruments, laser, fiber optics, optoelectronic devices and related optoelectronics system of hardware and software [1]. In recent years, optics plays a significant role in the growth and development of high tech industry such as energy generation, telecommunications, information technology, detection \& ranging, medical diagnostics and treatment, structure of health monitoring, quality control of products as well as in the environment control of our ambience [1].

Bangladesh is a country of about 140 million people and it has 16 public Universities and more than 50 private Universities. Most of these Universities have undergraduate and graduate programs in disciplines of Humanities, Social Sciences, Business Studies as well as Science \& Engineering programs. In response to the growing importance of optics, education institute across Bangladesh including the Rajshahi University (RU), a very old University in the country established in 1952, has been offering optics course in the Department of Applied Physics \& Electronic Engineering from the inception of the Department. The Department of Applied Physics \& Electronic Engineering at RU was established in 1966 and initially it had started to offer a Master of Science education program. The Department had late offered an undergraduate program in 1973. Optics and optoelectronics courses at RU are part of a 4-year Bachelor of Science Honors in Applied Physics \& Electronic Engineering degree program. A 2-credit project course is compulsory for all attending Honors graduate.

The main courses include Applied Optics, Basic and Advanced Electronics, Quantum Mechanics, Atomic \& Nuclear Physics, Pulse \& Switching, Instrumentation \& Control Systems, Non Conventional Energy, Integrated Circuits (IC) Fabrication \& Communication Electronics, Solid State Physics, Communication Engineering, Applied Geophysics, Medical Physics, Computer Architecture \& Organization, Radio \& TV Engineering, Telecommunication, Microprocessor \& Microcomputer, Materials Science and Advanced Solid State Physics. The Honors degree program is 4 years duration, comprising 160 credits, where 128 credits are allocated for theory courses and 32 credits for practical classes with project works. The education of RU

Tenth International Topical Meeting on Education and Training in Optics and Photonics, edited by Marc Nantel, Proc. of SPIE Vol. 9665, 96651E · @ 2007 SPIE, OSA, IEEE, ICO doi: $10.1117 / 12.2207927$ 
contains a formal lecture of 50 minutes duration and a laboratory session of 2 hours. The department offers a basic course of Applied Optics for the first year Honors students to have a fundamental knowledge in optics.

Optics and optoelectronic courses are embedded in Instrumentation \& Control Systems, Non Conventional Energy, IC Fabrication \& Communication Electronics, Solid State Physics, Communication Engineering, Materials Science and Medical Physics. In laser and fiber optics, students learn various aspect of laser such as principles of laser generation, laser resonator, beam properties, application in interferometry \& holography and application in medical physics. Light guiding properties of optical fibers, dispersion, attenuation, applications of fiber optics in telecommunication and in Satellite Communication as well as laser in various sensor applications. Besides, basic optics principles and their use in optical equipments as well as in technical applications are taught through lectures and practices. Discussed topics include interfrometry, diffraction, polarization and their applications through a number of demonstration classes.

\section{Project}

The main concern in the undergraduate project work is the syntheses of the knowledge from all lectures that have been in the classroom and its application to solve real problems in practice. Components and instrumentations are needed to construct the necessary project to carry out its measurements and to exhibit its performance to the audience present. The following two typical illustrations are among 50-project work usually done in every year by the Honors students at the end of their $4^{\text {th }}$ year degree program. The project was based on electronics \& optoelectronics with hardware and software design.

Design and construction of a microprocessor control four-way traffic signal system: Electronic auto traffic signal system is very useful for developing country like Bangladesh. It has very important role to make discipline in vehicle communication in a busy road. A microprocessor-based system is controlled by software; therefore it controls the duration of light ON/OFF to make order of the traffic systems.

Carbon dioxide gas detector: Whenever $\mathrm{CO}_{2}$ gas is passed through a fresh colorless lime water $\mathrm{Ca}(\mathrm{OH})_{2}$, it is turned milky in color due to its white precipitation of calcium carbonate $\left(\mathrm{CaCO}_{3}\right)$.

Colorless limewater + Carbon dioxide gas $\leftrightarrow$ White precipitated of Calcium Carbonate + Water.

Therefore, $\mathrm{CO}_{2}$ gas changes the optical transparency of the limewater. Their changes in transparency can be measured by using optoelectronic circuit and detect the presence of $\mathrm{CO}_{2}$.

\section{Examples of experiment for basic understanding}

The objective of running optics laboratory class is a provision of practical experience to supplement and illustrate concepts developed and discussed during formal lectures. With this in mind, various laboratory works are organized for the first, second, third and fourth year students. In the first year level, the courses are not very specialized so that the laboratory experiments involve certain common components and instruments. Exchange and reallocation of the equipments are possible during the execution of the yearly program. The motivating factors for local fabrication/assembling of optics experiments are: (i) to have fundamental knowledge in education (ii) cost-effectiveness (iii) easy maintenance and (iv) easy duplication, upgrading or modification. The exercise involves teaching staff members, technical staff members and the students also. Five sets of optics experiments are illustrated below which have been set for demonstration for students from the first year level to $4^{\text {th }}$ years.

\subsection{Phenomena of interference of light.}

Measurements of radius of curvature of a lens by Newton's ring: The set up is developed in the laboratory and is depicted in Figure 1(a). When a plano-convex lens L of large radius of curvature is placed on a glass plate $\mathrm{G}$, a thin air film of progressingly increasing thickness in all direction from the point of contact between the lens and glass plate is formed. The air film thus possesses a radial symmetry about the point of contact. When it is illuminated normally with monochromatic light, an interference pattern consisting of a series of alternate dark and bright circular rings concentric with the point of contact is obtained.[2, 3, 4] and it is shown in Figure 1(b).

Students usually measure the diameter of the lens and calculate the diameter, D, of dark and bright rings by using of microscope. By plotting a graph of the square of the diameter as the ordinate and number of rings as abscissa, the calculated result gives a straight line and it then determines the radius of the curvature of the lens by using the following equation

$$
\mathbf{R}=\frac{\left(D_{n+m}^{2}\right)-D_{n}^{2}}{4 m \lambda}
$$


Where, $\lambda$ is the monochromatic light wavelength $\mathrm{n} \& \mathrm{~m}$ are the number of rings, respectively.

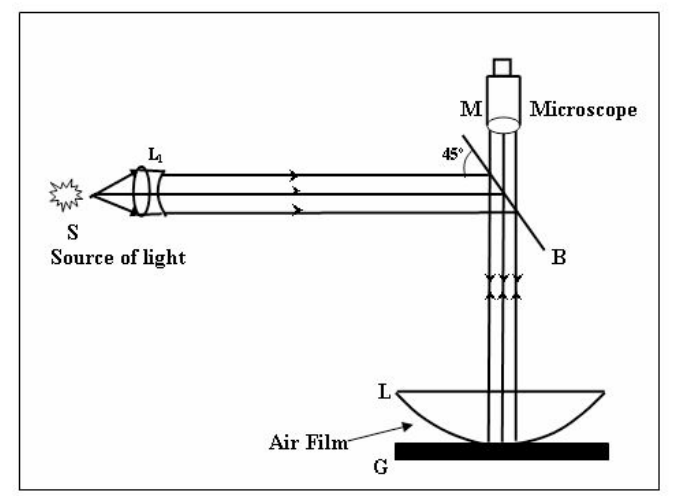

Fig. 1(a). Experimental set up of interference of light

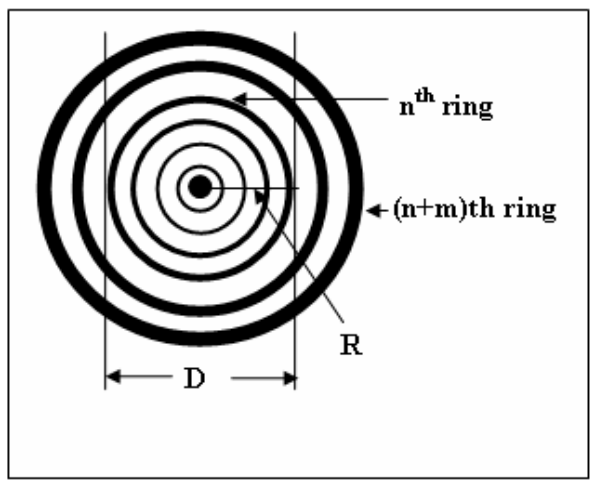

Fig. 1(b). Interference pattern

\subsection{The phenomena of diffraction of light}

Determination of the wavelengths of various spectral lines by spectrometer using plane diffraction grating: The laboratory experiment is summarized schematically as in Figure 2. If a monochromatic light of wavelength $\lambda$ falls normally on a plane diffraction grating placed vertically on a Prism Table, a series of diffracted image of the collimator slit will be seen on both sides of direct image [2, 3, 4]. Using the equation

$$
\mathbf{N}=\frac{\sin \theta}{\mathrm{n} \lambda}
$$

Where, $\mathrm{N}$ is grating constant, $\mathrm{n}$ is the number of the image and $\theta$ is the deviation angle of light.

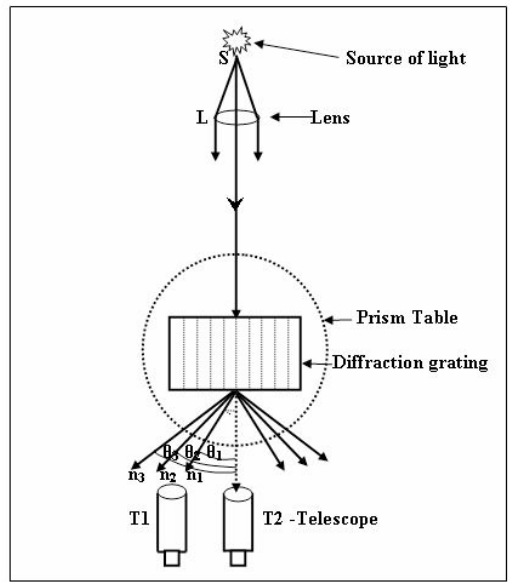

Fig. 2. Illustrates the diffraction phenomena of light.

The students usually do the experiment with sodium light of known wavelength and then the value of $\mathrm{N}$ is determined first. From the knowledge of $\mathrm{N}$, the wavelength of any unknown light can be found with the help of Equation (2).

\subsection{Phenomena of polarization of light}

Determination of the specific rotation of a sugar solution by polarimeter: Figure 3 illustrates the schematic set up of the experiment to have a basic understanding of the polarization of light. The angle of rotation of the plane of vibration produced by a substance, in solution or otherwise, is proportional to (i) the thickness of medium (solution) (ii) the concentration of the solution or the density of the active substance in the solvent and (iii) the nature of the substance. 


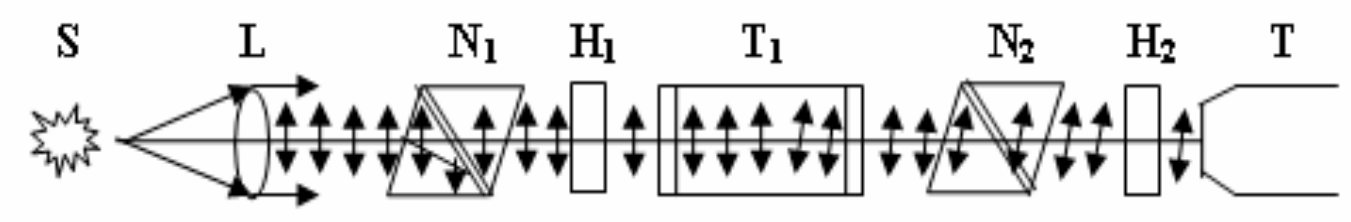

Fig. 3. Schematic diagram of the experiment of polarization of light

If $1=1$ decimeter and $\mathrm{c}=1 \mathrm{gm} / \mathrm{cm}^{3}$, then specific rotation may be defined as the rotation produced while traversing a path of one decimeter $(10 \mathrm{~cm})$ length in the solution containing $1 \mathrm{gm}$ of the optically active substance per $\mathrm{cm}^{3}$ of the solution.

The specific rotation $=($ rotation produced by 1 decimeter length of the solution $) /($ density of the solution in gm c.c.)

The amount of the rotation is usually determined from the experiment by the students and the rotation depends on the temperature as well as wavelength of the light used. The angle of rotation vs. their corresponding concentration of the solution yields a plot of straight line and it then determines the unknown concentration of the solution.

\section{Thin optical coating}

It is well known $[5,6]$ that one can improve the properties of the glass by use of very thin surface coatings. For example, one can diminish the inflow of solar energy to $50 \%$ (during the summer), without changing the visible appearance with one type of coating. Another type can be transparent to solar radiation but decrease the out flow of heat (during the winter) to $50 \%$ of the magnitude in a normal uncoated glass $[5,6]$.

In large parts of the world the climate is "Warm" during the summer and "Cold" during the winter. It is clear that to improve the quality of livings, to minimize the energy needs in the livelihood and to efficiently utilize the energy consumption, scientists all over the globe are engaged in research on selective surface coating and energy efficiency. The key concept of spectral selectivity is that the glass coatings should have qualitatively different optical properties in different wavelength ranges [5, 6, 7]. A low emittance coating is of particular importance in a cold climate where the coating has unity transmittance for luminous \& solar radiation in the wavelength range $0.3<\lambda<3 \mu \mathrm{m}$ and unity reflectance or zero emittance in the $3<\lambda<50 \mu \mathrm{m}$ wavelength range [ 8 , $9,10]$. The solar control coating is useful in hot climate and the ideal coating should be transparent for visible radiation in the wavelength range $0.4<\lambda<0.7 \mu \mathrm{m}$ and have unity reflectance at wavelengths $0.7<\lambda<3.0 \mu \mathrm{m}$. With this concept in mind, our group at RU is engaged in research on thin optical coating of metal, semiconductor or even insulating films to make of their use in selective surfaces and devices.

\subsection{Specialized experiments on thin optical coatings}

Determination of thickness for thin coatings: The objective of this particular experiment is to deposit thin metal or semiconducting thin films and to determine of their thickness as well as of their transmission \& reflection coefficients. For deposition of thin films, a vacuum coating unit (Edwards Vacuum Ltd. England) was procured and it has the options to produce the thin films by thermal evaporation as well as by e-beam evaporation technique [11]. To measure the optical properties of the thin coating, our department obtained a Perkin-Elmer, Lambda-19 spectrophotometer as a generous donation by International Science Programs (ISP), Uppsala University, Sweden.

Student in the $4^{\text {th }}$ year Honor's level usually carry out their projects on thin optical coatings. The bench setup for determination of the thickness of thin coatings is shown in Figure 4(a). The interference method for the determination of film thickness was done by a method developed by Tolansky [12] to a remarkable accuracy. When the interferometer is illuminated with a parallel beam of monochromatic light, a fringe system as shown in Figure 4(b) is produced. The displacement $\mathbf{I}$ of the fringes system across the film-substrate step is then measured to calculate the film thickness $\mathbf{t}$ using the relation

$$
\mathbf{t}=\frac{\mathbf{I}}{\mathbf{h}} \times \frac{\lambda}{2}
$$


where, $\mathbf{h}$ is the fringe height. In this method, the thickness measurement of 3 to $2000 \mathrm{~nm}$ can be done with an accuracy of $\pm 1 \mathrm{~nm}$.

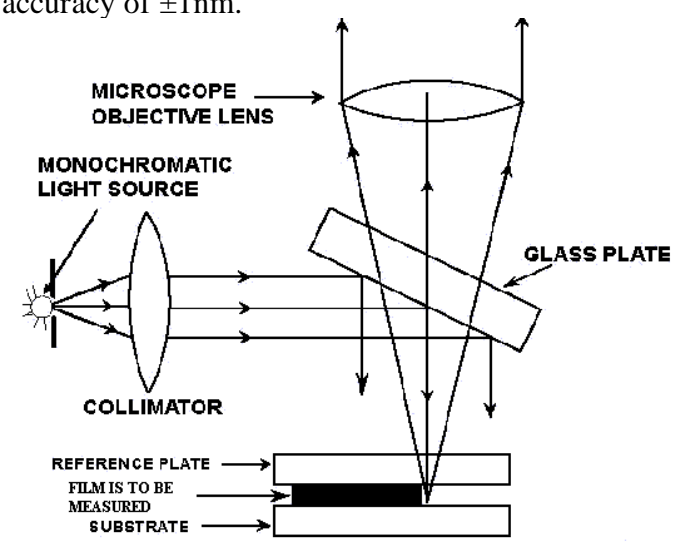

(a)

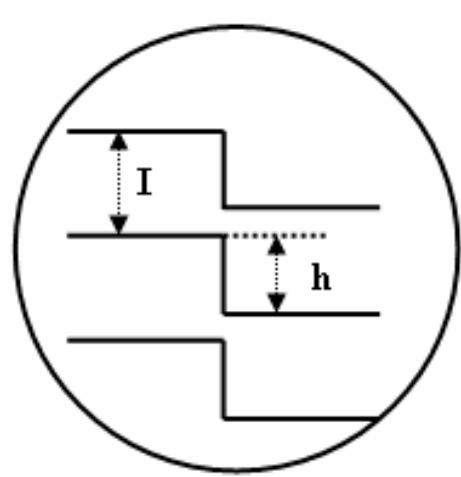

(b)

Fig. 4(a). Enlarge view of the interferometric arrangement for the measurement of film thickness; (b) The fringe pattern with step height ' $h$ ' and fringe spacing ' $\mathrm{I}$ '.

Determination of optical band gap \& refractive index: The objective of the experiment is to study the percentage of transmittance $(\mathrm{T})$ and reflectance $(\mathrm{R})$ of thin coatings obtained by its deposition of selected metal or semiconducting films in the selected wavelength range. From the obtained data of transmittance and reflectance spectra, the percentage of absorption (A) is to be calculated. Sample index of refraction is determined indirectly by measuring the transmittance as well as the thickness data by the conventional relation

$$
\mathbf{n}=\frac{\mathbf{A}_{\mathbf{n}_{\mathbf{0}}}}{\mathbf{T}} \times \frac{1}{\ln \left(\frac{1}{\mathbf{T}}\right)}
$$

where, $n_{0}$ refractive index of glass substrate $\left(n_{0}=1.5\right)$. From absorption data, the coefficient of absorption in the selected energy interval of the optical spectra helps to determine the optical band gap of the sample.

\section{Conclusions}

It is shown in our article that without using any sophisticated equipments, the optics education could be conducted in our laboratory and it helps to make understanding of the students the basic concept of optics The development of optics and photonics education requires a large number of well trained and motivated teachers and technicians who should discharge their experiences in teaching to the students efficiently. Most of the research and development in the area of photonics involves the use of optic fiber. We are now planning to revisit our experimental set-up by fiber optic based interferometer in addition of our conventional set-up. The science and teaching methods are truly international and this workshop provides a venue and opportunity for teaching and learning of the participants and has the capacity to bring people closer in both a professional and personal way.

\section{Acknowledgments}

Author is gratefully acknowledging the helps in discussion concerning the preparation of the manuscript to Mr. Rezaul Islam and Mr. S.M.A. Motakabber, colleagues in the Department of Applied Physics \& Electronic Engineering, University of Rajshahi, Bangladesh. Author is also indebted to Mr. Sazzad Hossain, Ph.D. research fellow to help in drawing of the diagrams as well as for typing and editing the manuscripts.

\section{References}

[1] LASERS, "Principles and Applications", Wilson \& Hawkes (Prentice Hall), ISBN O-135-23697-5.

[2] A. Giasuddin, "Practical Physics", $3^{\text {rd }}$ Edition, Published by Hafiz Book Center, Dhaka-1205, Bangladesh, (1992).

[3] M. Kalimuddin, "A Text Book of Practical Physics", $4^{\text {th }}$ Edition, Mallick Brothers, Dhaka, Bangladesh, (1976).

[4] N. Subrahmanyam \& Brijlal, "A Text Book of Optics", S. Chand \& Co. Ltd, New Delhi, (1999).

[5] C. G. Granqvist, "Radiative Heating and Cooling with Spectrally Selective Surfaces", Appl. Opt. 20, 2606 (1981).

[6] C. G. Granqvist, "Specially Selective Coating for Energy Efficiency and Solar Applications", Physica Scripta. 32, 401 (1985).

[7] C. M. Lampert, "Solar Optical Materials for Innovative Window Design", Int. J. Energy Research, 7, 359 (1983).

[8] C. M. Lampert, "Electronic Materials and Devices for Energy Efficiency Windows", Solar Energy Mater., 11, 1 (1984).

[9] C. G. Granqvist, "Electricity", edited by John soon, T. B. Bodlund, B. Williams, R. H. Lund University Press, (1989).

[10] C. G. Granqvist, "Spectrically Selective Surfaces for Heating \& Cooling Applications", SPIE, Optical Engineering Press, Bellingham, Washington, (1989).

[11] K. L. Chopra, "Thin Film Phenomena", MacGraw Hill, New York, (1969).

[12] S. Tolansky, "Multiple Beam Interferometry of Surfaces \& Films, Oxford University Press, New Jersey, (1948). 